bodily health, and rid of a serious local disease, the patient left the hospital on the eighth week from the day of operation, in a condition soon to resume his employment, and but slightly mutilated.

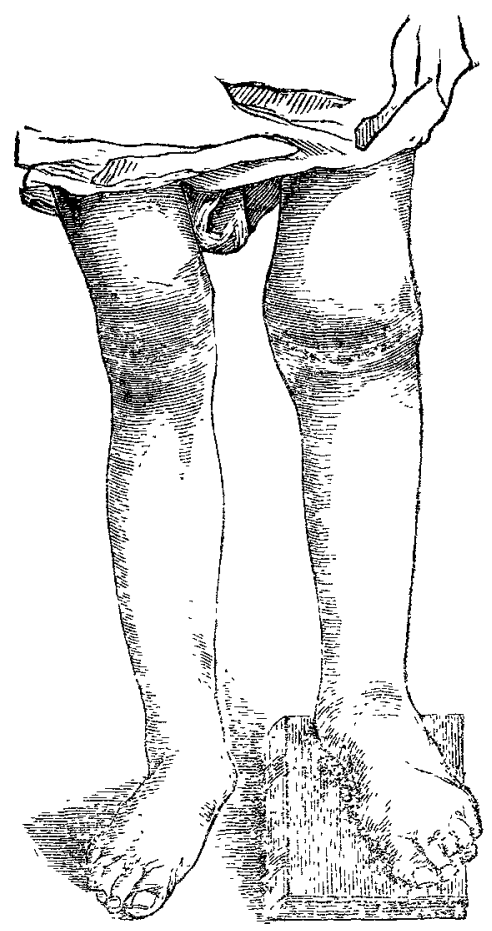

The accompanying woodcut, excctly representing the condition of the limb eight weeks after removal of the joint, was taken by Dr. Westmacott. The swelling of the lower limb, and the slightly-puffy condition of the parts immediately in volved in the operation, are truthfully represented.

I look upon the result, in this case, with feelings of great satisfaction, and regard it as a marked triumph for conservative surgery. It is the opinion of many of my colleagues, as well as my own, that had amputation through the thigh been adopted, instead of the less formflable operation of excision, the man would have stood a less chance of recovery; indeed, T have reason to know that amputation of the limb had been seriously considered, but that those who consulted about its propriety, before his arrival in London, had refused to operate, thinking that the patient's state of health was in too shattered a condition to admit of its performance.

Green-street, Grosvenor-square, Nov. 1859.

\section{REPORT OF A CASE OF}

\section{PARALYSIS AGITANS REMOVED BY THE CONTINUOUS GALVANIC CURRENT.}

\section{By J. RUSSELL REYNOLDS, M.D. LOND., F.R.C.P.,} ASSISTANT-PHYSICIAN TO THE WESTMINSTER HOSPITAL,

W. F- male, aged fifty-seven; married at the age of twenty, and the father of twelve children; height, $5 \mathrm{ft} .10 \frac{1}{2} \mathrm{in.}$; weight, under 11 st. No anatomical deformity; no hereditary predisposition to disease; has had good health; has lived well and temperately. His occupation is that of a carpenter; he has resided in a healthy locality, and has never, until the commencement of his present illness, suffered from anything of a similar kind.

For the last five years he has had anxiety with regard to his children, and distress at parting from them, but he cannot definitely refer his malady to this cause. During the last two years he has noticed occasional tremor of the right arm and leg, the latter being affected less frequently and less severely than the former. The tremor has occurred if he (1) has been "put out about anything;" (2) has attempted to lift anything very heavy; (3) has "taken cold ;" (4) has lifted liquid in a cup to the mouth; or (5) has fully extended the arm and forearm, and pressed anything firmly with the palm of the hand. But under all these circumstances the tremor has ceased when the "exciting cause" has been removed, and it has never been so severe as to prevent him, from following his occupation, which is one requiring much exertion and accurate direction of movements

For the last six or eight months he has suffered occasional vertigo-i, e,, a "feeling as if he should fall, or pitch on his head; and as if the head were tied up in tight bandages." At the same time there has been darting pain through the head.

On September 20th he was at work as usual-was alternately stooping down and lifting over his head-when he suddenly felt vertigo, aching in knee-joints, and general disturbance; and at the same time violent shaking occurred in the right upper extremity. The agitation of the right arm continued througbout the day, but stopped at night. It returned on the following morning, as soon as he moved.

On October 5 th he was first seen by myself, and on this day (the fifteenth from its commencement) the agitation was ex. treme. Nevertheless, it had always ceased during the night; and, on two occasions, for about an hour, and without assignable cause, during the day. He thinks it is arrested at night by pressing the anterior surface of the forearm against the crest of the ilium. With the exceptions above mentioned, the movements of the arm have been much the same as now seen; being occasionally aggravated, but not much, by emotional disturbances, or by the attempt at voluntary movement of the extremity.

The whole of the right upper limb is involved-i. e., the hand moves on the forearm, the forearm on the arm, the arm on the shoulder; but the most constant and most extensive movement is that at the elbow-joint; the least constant and least extensive is that at the shoulder. Almost every direction of movement possible in the upper extremity is performed; from 22 to 24 double movements occur in five seconds, and the range of movement at the hand, when, for example, the jerking is principally that of fiexion and extension of the forearm, varies from nine to ten inches. The movement, therefore, amounts to about eight feet per second.

To the patient himself the right arm feels hotter than the left, and a difference of temperature is very obvious to the hand of the observer. Temperature over left biceps, $87^{\circ}$ Fahr.; over right, $91^{\circ}$.

The involuntary movement of the arm can be arrested by his lying on the sofa, and pressing the forearm against the ilium; but any attempt to move the limb voluntarily at once reproduces the shaking, although he remains in the recumbent posture. The movement is, moreover, instantly arrested by my firmly grasping either the forearm in any part of its upper two thirds, or the arm in its lower third. This is not a mere mechanical arrest of the movements, for it cannot be effected by holding the wrist; and the jerking recommences if, while the extremity is grasped in the manner described, the patient makes any attempt at a voluntary movement. The pressure is not painful, nor is it so directed as to arrest the circulation.

The mental condition of the patient, and his general health, appear unaffected.

Sensibility is unchanged in the right upper extremity; there is no deviation of the tongue, nor distortion of the features. He can walk well, and without dragging either leg; there is only occasionally slight tremor of the right leg.

A continuous galvanic current (direct) was applied to the arm and forearm, the movements of the latter being at the time arrested by pressure. At the end of five minutes he could execute voluntary movements without the least tremor, and emotional excitement failed to reproduce the jerking. The temperature of the two arms, examined after the current had been passing for half an hour, was equal. The involuntary movements did not return until three hours after the current was discontinued; they then reappeared, and continued through. out the evening; stopped at night, but returred on the follow. ing morning.

October 6th. - The current was applied while the arm was in violent movement, but in two minutes it became perfectly still. Application continuer for an hour.

7th. - Last evening there was no jerking nor tremor for five hours after the current was discontinued; then it commenced, but stopped spontaneously in about half an hour, and during the remainder of the evening there was nothing more than very trifling tremor. The jerking has returned this morning, but is much less than on the first day of observation. There are but twenty alternations in fifteen seconds, and the range of movement is from three to four inches. The movement therefore, is only 86 foot per second-less than one-eightn of what it was three days ago.

The current was applied on the 7 th, on the 8 th, and 10 th $_{3}$. and after the 10th-i. e., after five applications, - the sponta. 
neous jactitation completely ceased. When any weight is held in the hand, and it is lifted towards the mouth, there is tremor; but this is slight, is not more than has occurred for the last two years, and it immediately ceases when the effort is discontinued. The arm and hand are weak; every movement can be executed by them voluntarily, but such movements are feeble.

28th. - Has written me a letter in a good and legible hand.

The current was applied about every other day, for an hour, antil Nov. 10th, and during this time there was steady increase in the power of the limb, and the jactitation did not return. No medicine of any kind was given.

November 12th. - Quinine and iron were ordered.

15th. -W. $\mathrm{F}$ - is in perfect general health; there is no jactitation, and only the slight tremor already described when the hand, with something in it, is raised towards the mouth.

The current employed in this case was derived from a Pulvermacher's chain battery of 120 links.

The above case requires, I think, no comment. It is more important that a fact of this character should be placed on record than that any speculation should be advanced in regard to the pathology of "paralysis agitans," or the modus operandi of the continuous galvanic current. The term which I have employed to denote the case involves no theory; it is but the name of a prominent symptom - a symptom which, in this instance, constituted almost the whole of the affection, and which, after a fortnight's duration without the slightest tendency to improvement, was quickly, but progressively and effectually, removed by a special form of treatment.

That this result of the continuous current is not to be attributed to mere accidental coincidence is, I think, evident from the history of the case. Moreover, a similar result appears to have been obtained by Remak. In Schmidt's Jahrbiicher, Jahrg., 1957, bd. 94, p. 102, there is the following entry:"Paralysis agitans, bei einem 60 jühr. manne in 15 sitzg. beseitigt."

Grossenor-street, Norember, 1859.

\section{CONTRIBUTIONS TO UTERINE PATHOLOGY.}

By E. J. TILT, M.D., M.R.C.P.,

SENIOR PHYSIOIAY TO THE FARRIYGDON GENERAL DISPENSARY AND IYING-IN CHARITY.

CHPONIC UTERINE DISEASE; H AMORRHAGE FROM THE BOWELS FOR THE LAST TWENTY YEARS; INTERNAL HEMORRHOIDS; DEBILITY; NERVOUS SYMPTOMS.

Iv the early part of last September, I was consulted by Mrs. —, a delicate-looking lady, of middle stature, and embonpoint, with the peculiar pallid hue of those who have long suffered from loss of blood, and a gait indicating long-continued abdominal pain. The patient was thirty-four years of age, and her family antecedents were good. She had been a delicate child; the menstrual flow appeared at fourteen years of age, but did not become regular until the eighteenth year; and during the interval her health was bad. About that time she began to pass blood by the bowels, and has continued to do so, off and on, up to the present time. This passing of blood with the motions did not weaken the patient, unless it were long continued, so that nothing was done to prevent it; and it never came at catamenial periods, except during the past year. The patient remembers that, even at an early age, she wonld be obliged to sit down, sometimes for half an hour after a motion, on account of pain in the fundament. The lady married at twenty-six, and has had four children. The last pregnancy occurred a year and nine months since; it was distressingly painful, and the child was born at seven months. Her health has been worse ever since; the loss of blood had been more frequent, seldom missing for more than eight days; and last winter the patient was twice confined to her bed by severe abdominal pain, with continued passing of blood by the bowels, for which she was attended by two medical men-one a physician of high standing in a large provincial town. The patient had ceased to have medical advice for several months, but had never recovered her health; and having been troubled with diarrhcea whilst at the sea-side, she came to town for advice.

My first object was, of course, to get rid of this disagreeable complication; and I soon did so, by small doses of blue-pill and extract of opium, and by the exhibition of opiates by the rec- tum. The nitrate of bismuth, in large doses, diminished greatly the intestinal irritation, and the patient soon felt very much better than she had for a long time. 'The tongue was very good; the appetite excellent-of ten ravenous; digestion good; but the bowels often distended with flatus, irritable, and the seat of strange sensations and flutterings. She often felt as if she were sea-sick. Sulden sensations of faintuess frequently arose; the bowels would be moved, with or without blood; and this afforded relief. The bowels generally acted two or three times a day; sometimes with prolapsus of the rectum. The patient was sure the blood did not come from the prolapsed rectum, but that it trickled through it in small quantities; she being under the impression that the blood would have continued to flow so long as she used the vessel. The rectum was often the seat of distressing sensations of aching, which would last half an hour or more. This sometimes came on spontaneously, was oftener caused by the action of the bowel, and rendered the sitting posture intolerable. The frequent flow of blood from the intestine was evidently only a symptom of some deepseated pathological condition, seriously implicating the functions of the bowels. The blood could not come from far, for it was always red and fluid-never black and like coffee-grounds.

On examining the rectum, the finger did not find the passage hot or very irritable; the sphincter contracted spasmodically. there were a few internal hæmorrhoids, but so soft, flaccid, and irritable, that they had escaped the notice of previous medical advisers. On being brought in view, they were pale, although the patient had passed blood that morning, and the finger came back untinged with blood. It was evident to me that the blood had not come recently from the internal piles, and after careful study of the case, I do not think the blood has habitually come from them. To admit this would be to admit that the patient had internal piles since puberty, which is contrary to what is generally observed. Pursuing my investigation, per rectum, 1 found the body of the womb considerably enlarged, its surface irregular, and imparting a sensation of stony hardness to the finger. Impacted in the womb, and projecting from it, there was a fibrous growth, about the size of a cob-nut, movable, and intimately connected with the rectum.

This peculiar condition of the womb seems to me the structural cause of the long-continued entorrhagia. It may so implicate the bloodvessels of the lower part of the intestine as to cause their congestion, and the exhalation of blood from the intestinal surface, so often as the patient's active digestive powers brought the portal system above a certain average of fulness; thus accounting for the fact of the issue of blood last. ing so long without materially damaging the system. On exa. mining the patient by the vagina, I found both lips hypertrophied, or, rather, there was a soft, red, hypertrophied substance growing from the lower portion of each lip. They were not very painful, and did not bleed on pressure; there was no vaginitis, but a good deal of leucorrhoea. Considering the hard swelling of the body of the womb to be almost beyond the pale of treatment, I thought it desirable to cure the subacute in. flammatory affection of the neck of the womb, and I advised the patient to return to town in a few weeks, and place herself under the care of Dr. H. Bennet, advising, in the meantime, a solution of acetate of lead to be used as an injection twice a day. Dr. Bennet took the same view as myself; he applied potassa fusa cum calce to the two hypertrophied projections, and when, on Dr. Bennet's retirement from practice, I again took charge of the patient, the ulcerations were healing favourably. Tincture of iodine was frequently applied to the neck of the womb; the injections were continued, so that after six weeks' treatment, the morbid growths of the neck of the womb were so much reduced, and so indolent, that they might be safely left alone, or without other treatment than injections. No alteration had taken place in the body of the womb. For six weeks mild tonics, the citrate of iron, the nitrate of bismuth, were successively tried; they prevented the flow of blood from the bowels, but had no other good effeot. By doing this they may have, perhaps, increased the feelings of abdominal irritation and distension which frequently made the patient say that she continually felt as if she were going to be ill. At all events, these miserable sensations were alleviated when she again passed blood for a few days, previous to her returning home. The painful aching of the anus was only partially relieved by the use of linseed-tea injections to move the bowels, their action being followed by the injection into the rectum, with a one-ounce india-rubber bottle, of a tablespoonful of the following lotion in the same quantity of warm milk:-Tincture of hyoscyamus, one ounce; laudanum, two drachms; water to four ounces: a scruple of extract of bellatonna being sometimes added. 